\title{
Availability and sufficiency of phenobarbital, an essential medication, in Bhutan: a survey of global and neuropsychiatric relevance
}

Devender Bhalla ${ }^{1,2,3^{*}}$

\begin{abstract}
Objective: We aimed to provide a reliable evidence-based conclusion around manufacturing, import, availability and sufficiency of one essential medication, phenobarbital (PB) through our example location (Bhutan). The relevant details about manufacturing, import, annual quantity, dose strength were obtained.

Results: There was no local manufacturing of PB and all other anti-seizure medications. A total of 1068 vials of PB $200 \mathrm{mg} / \mathrm{mL}$ inj and 489,350 tablets of PB30 mg (i.e. 14.6 kilos) was estimated to annually become available. Of this, $5.3 \mathrm{k}$ (36.3\%) was present at the basic health units (BHUs). The PB was absent at 26 (14.7\%) BHUs. There was no availability of PB syrup. Treating supposed target of $50.0 \%$ of the $20.0 \%$ of the prevalent case-load $(N=4523)$ require 18.1 kilo of PB annually. To conclude, having or not the local manufacturing may or may not be a limitation. There is a need to overcome challenges of inappropriate dose strength, absent pediatric formulation, indirect cost, and low selling price of PB. The possible therapeutic participation of PB in managing disease conditions (like epilepsy) remains limited despite favorable safety and efficacy profile. Strengthening the availability of essential medications is essential to reduce the treatment gap and public health burden of treatable disease conditions.
\end{abstract}

Keywords: Anti-epileptic drugs, Epilepsy, Phenobarbital, Treatment gap

\section{Introduction}

Phenobarbital (PB) is a recognised essential medication that is indicated for epilepsy and other chronic conditions of global interest, such as anxiety, insomnia, barbiturate addiction, etc. Being essential implies that " $P B$ satisfies the priority healthcare needs of the population to which there should be access at all times in sufficient quantity (and in a similar manner across regions)" [1]. Fulfilling this goal is important since patients are likely to die more from treatable conditions (than those which are not) as they may not receive timely or appropriate medication [2]. The risk is even more if those medications are fundamental $[3,4]$ or are the only ones that are available,

\footnotetext{
*Correspondence: autoresponse@africamail.com

${ }^{1}$ Sudan League of epilepsy and Neurology (SLeN), Khartoum, Sudan

Full list of author information is available at the end of the article
}

feasible, or affordable for the majority of patient population [5-7]. A vital first step to improve access (and therefore coverage) to essential medications is to know their availability in the retail market as well as in the national distribution list. Thus, continuing with our vision of establishing a reliable neurological (and mental health) profile and international positive presence of scientifically-silent locations, and with an objective to provide reliable conclusions around manufacturing, import, availability and sufficiency of one essential medication (i.e. $\mathrm{PB}$ ) in our example location (Bhutan), we performed this work. This, if validated, may in-part help to understand access to essential medications and an actual pattern of demand-and-supply before proposing improvements in resource development in neuropsychiatry.

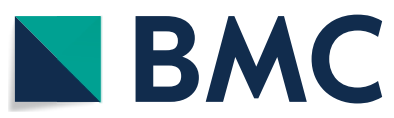

(c) The Author(s) 2018. This article is distributed under the terms of the Creative Commons Attribution 4.0 International License (http://creativecommons.org/licenses/by/4.0/), which permits unrestricted use, distribution, and reproduction in any medium, provided you give appropriate credit to the original author(s) and the source, provide a link to the Creative Commons license, and indicate if changes were made. The Creative Commons Public Domain Dedication waiver (http://creativecommons.org/ publicdomain/zero/1.0/) applies to the data made available in this article, unless otherwise stated. 


\section{Main text \\ Methods \\ Why Bhutan? What source of medical service? What source of medication?}

Bhutan is a small landlocked low middle-income Asian country, Fig. 1, with a population of 757,042 (69.1\% rural; $52.5 \%$ males; density $16.3 / \mathrm{KM}^{2} ; 5.9 \%$ aged $65+$ years; $29.0 \%$ aged 0-14 years; life expectancy 71.0 years) [8]. Only $62.0 \%$ Bhutan is paved with poor health indicators for those living at the mountainous terrain in comparison to plains [9]. Bhutan has about 185 (average 1 for 4313 residents) basic health units (BHUs). Its healthcare is entirely public with $100 \%$ cost-free unconditional medical service [10] although indirect costs (such as time, travel, etc.) remain.

\section{What significance of $P B$ (developed and resource-poor countries)?}

The relevance of $\mathrm{PB}$ differs from person-to-person and region-to-region, depending upon which side one wishes to look at. Generally, PB has a broad anti-seizure (partial and generalised) activity, including neonatal seizures and $<20$ min status epilepticus. In resource-poor countries, $\mathrm{PB}$ is fundamental, most widely used, and often times the only available or affordable ASM $[3,6,11]$. In developed countries where neurotoxic concerns of $\mathrm{PB}$ are reportedly 'felt' more, other ASMs have superceded but not necessarily for the right reasons $[6,12,13]$. The position of $\mathrm{PB}$ has also been compromised due to its low retail price (low profit margin) and inappropriate marketing of its safety profile. For instance, discontinuation of $\mathrm{PB}$ due to actual occurance of side effects was none over 1 year [11] or $1.0 \%$ over 2 years [14] or merely $0.6 \%$ among children [15]. Thus, supposed greater withdrawal of $\mathrm{PB}$ is merely out of this perceived fear [16]. Unlike what is often projected, PB is not an "exclusive" [17], if at all (currently unpublished, D Bhalla 2018), subject of drug abuse [18]. None of the ASMs are superior in efficacy than $\mathrm{PB}[6,11,15]$ and generally those who do not respond to $\mathrm{PB}$ may also not necessarily respond to other ASMs even after four or five regimens [19]. Yet, PB remains "missing in action" [20]. One real disadvantage of $\mathrm{PB}$ is its low retail price because it leads to little profit margins unlike other ASMs (Field data, D Bhalla 2016) and that in return for severe restrictions and obligations often imposed exclusively $[3,4]$ on its business $[6,7]$.

\section{Data collection}

For manufacturing, there was one partially-established pharmaceutical manufacturer. For import, all medication (including $\mathrm{PB}$ ) supplies are imported once per year principally through one centralized department which distribute medicines later-on to all existing health facilities of the country [21] which provided required basis for deriving required estimates on $\mathrm{PB}$ for the whole country. For convenience, the scope of this project was limited to PB alone, excluding other ASMs [3]. All data was entered into MS-excel and analysed. The results

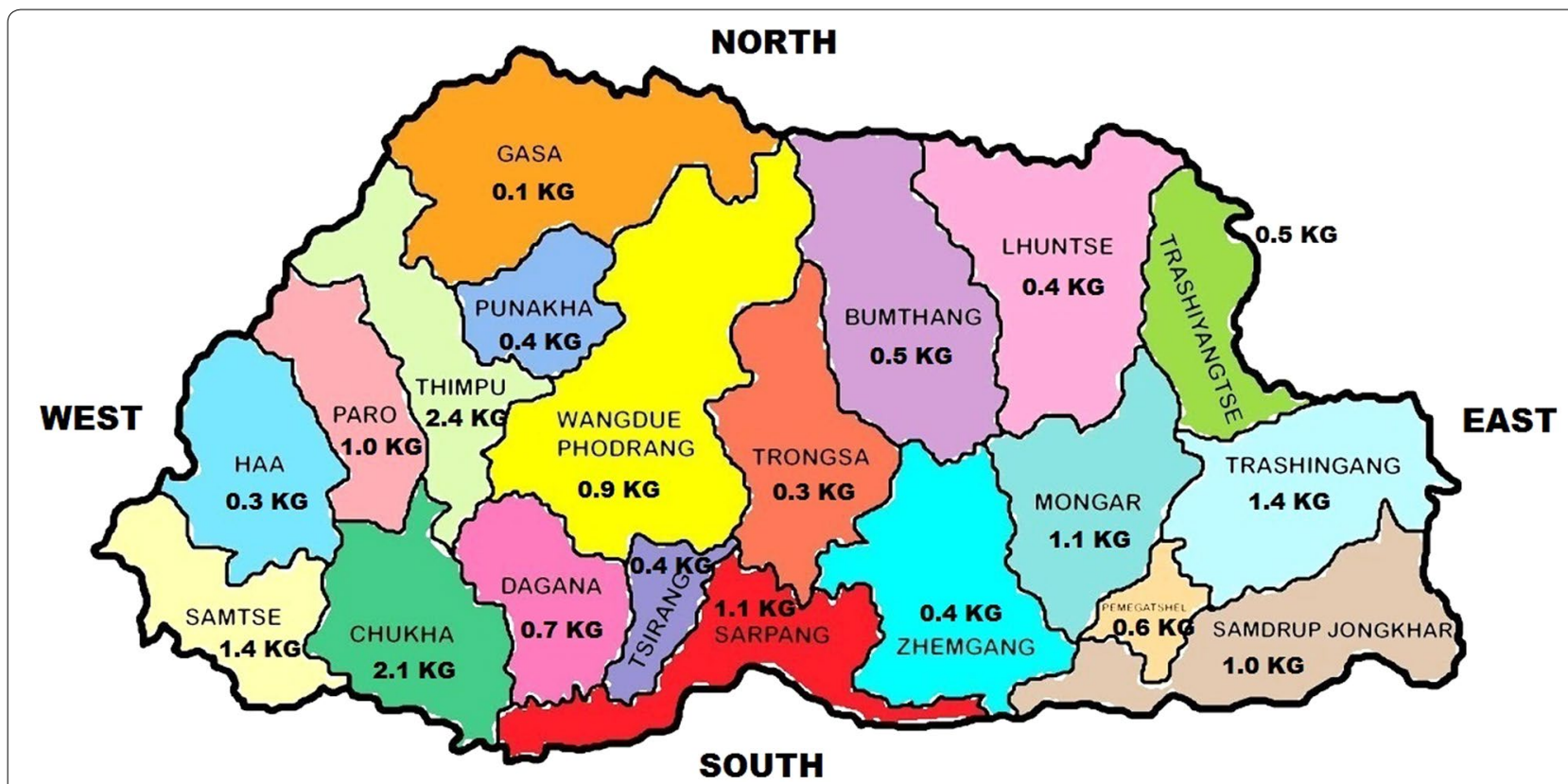

Fig. 1 Administrative divisions and depiction of annual in-part requirement of phenobarbital in Bhutan. Kg: the quantity of PB (in kilogram) that is expected to be annually required vis-a-vis prevalent case-load of epilepsy in different divisions of Bhutan 
are presented as count, frequency, mean or median with respective $95 \%$ confidence interval (CI) wherever deemed suitable.

Besides this, for epilepsy we analysed sufficiency of $\mathrm{PB}$ (i.e. annual availability vis-à-vis annual requirement) for meeting epilepsy-related goals [7, 22] in Bhu$\tan$. For this, we assumed that $20.0 \%$ of total prevalent epilepsy patient population (PEP) would receive a treatment during first implementation year. Of these 20.0, $50.0 \%$ would receive $\mathrm{PB}$ and remaining $50.0 \%$ would receive other ASMs or other treatments. This PEP was estimated by using an expected epilepsy prevalence of 6.0/1000 [23] and related population data of Bhutan [24]. So, sufficiency was calculated for this scenario as follows:

$$
\text { Target Population }(\mathrm{TP})=([\mathrm{PEP} / 5]) / 2
$$

$$
\text { Sufficiency }(\mathrm{S})=\text { ADD }(*) 365 \text { days of year }(*) \text { TP }
$$

An average daily dose (ADD) of PB over an annual treatment period was estimated elsewhere in rural Asia by the author to be $110 \mathrm{mg}$ (per person) to obtain lasting seizure control [11].

\section{Results}

Manufacturing and import of PB (frequency, quantity, dosage, administration form)

There was no local pharmaceutical manufacturing of $\mathrm{PB}$ (and other ASMs) in Bhutan. For import, during one calendar year (2016-17), a total of 1068 vials of PB $200 \mathrm{mg} /$ $\mathrm{mL}$ inj (1 mL vial) and 489,350 ready-tablets of PB $30 \mathrm{mg}$ had been imported. This translates to $14,680,500 \mathrm{mg}$ or $14.6 \mathrm{k}$ of PB. Of this, BHUs received 163 vials $(15.2 \%)$ of $\mathrm{PB}$ inj and 178,200 (36.4\%) of PB $30 \mathrm{mg}$ tablets (or $5.3 \mathrm{k}$ of $\mathrm{PB})$. PB was noted to be absent at 26 BHUs (14.7\%). No PB pediatric syrup was being manufactured and imported.

\section{Epilepsy patient load and sufficiency of PB for the first implementation year}

By using an expected epilepsy prevalence of 6.0/1000 [23], about 4536 patients with lifetime epilepsy are present in Bhutan. This number (and relative medication requirement) varies by region, as shown in Table 1 . What proportion among them constitutes active epilepsy is not currently known. As explained above on page seven, by taking a lliberal scenario of treating $50.0 \%$ of the $20.0 \%$ prevalent epilepsy patients with $\mathrm{PB}$ (i.e. $\mathrm{N}=[4536 / 5] / 2$ ),

\begin{tabular}{|c|c|c|c|c|c|c|}
\hline Province & Population & PEP & Target pop & $\begin{array}{l}\text { PB requirement/year } \\
(\mathrm{Kg})\end{array}$ & $3 \mathrm{Km}(\%)$ & $P / D$ \\
\hline Bumthang & 18,965 & 114 & 11 & 0.5 & 75 & 7715 \\
\hline Chhukha & 88,342 & 530 & 53 & 2.1 & NA & 4908 \\
\hline Dagana & 27,522 & 165 & 16 & 0.7 & NA & NA \\
\hline Gasa & 3,694 & 22 & 2 & 0.1 & NA & 3694 \\
\hline Haa & 13,499 & 81 & 8 & 0.3 & 71 & 1227 \\
\hline Lhuentse & 17,618 & 106 & 11 & 0.4 & 87 & 17,201 \\
\hline Monggar & 44,259 & 266 & 27 & 1.1 & 89 & 2168 \\
\hline Paro & 43,167 & 259 & 26 & 1.0 & NA & 10,415 \\
\hline Pemagatshel & 25,176 & 151 & 15 & 0.6 & 68 & 8394 \\
\hline Punakha & 17,715 & 106 & 11 & 0.4 & NA & NA \\
\hline Samdrupjonkhar & 39,961 & 240 & 24 & 1.0 & NA & NA \\
\hline Samtse & 60,100 & 361 & 36 & 1.4 & NA & NA \\
\hline Sarpang & 45,637 & 274 & 27 & 1.1 & 93 & 2985 \\
\hline Thimphu & 98,676 & 592 & 59 & 2.4 & 94 & 1015 \\
\hline Trashigang & 56,168 & 337 & 34 & 1.4 & NA & 9361 \\
\hline Trashiyangtse & 20,874 & 125 & 12 & 0.5 & 72 & 5139 \\
\hline Trongsa & 13,419 & 81 & 8 & 0.3 & NA & NA \\
\hline Tsirang & 18,667 & 112 & 11 & 0.4 & NA & NA \\
\hline Wangdue & 36,922 & 222 & 22 & 0.9 & NA & NA \\
\hline Zhemgang & 18,636 & 112 & 11 & 0.4 & NA & NA \\
\hline
\end{tabular}

Table 1 People with epilepsy and annual in-part requirement of PB across different divisions of Bhutan

Annual requirement of PB100 mg tablets is based on prevalent lifetime epilepsy pool of patients. Target population was defined as treating $50.0 \%$ of the $20.0 \%$ of the prevalent epilepsy population (i.e. column 4)

$3 \mathrm{Km}$ proportion of population within $3 \mathrm{Km}$ walking distance, $N A$ no information available, $P E P$ prevalent epilepsy population, $P B$ phenobarbital, $P / D$ number of persons per doctor 
the annual requirement of $\mathrm{PB}$ for epilepsy during first implementation year then comes at $18.1 \mathrm{k}$. This requirement during subsequent years may change depending principally upon how many move in and out of this target population pool, for each evaluation period.

\section{Discussion}

In Bhutan, there is no fully-established local pharmaceutical manufacturing and medicine supplies here depend entirely on import. So, the first question may include the pros and cons of local pharmaceutical manufacturing. In other rural countries, like Cambodia, the health department produces its own PB brand (Field data, D Bhalla 2010). Elsewhere, while some prefer small countries like Bhutan to rely on import for [25], others suggest establishing a local pharmaceutical industry [26] as it may provide direct positive impact on the country's economic development [27]. There may not be any clearcut answer to this but, whether desired or not, the pharmaceutical import remains largely a necessity. For instance, $90 \%$ of the medicines available in sub-Saharan Africa are imported from outside [26]. This is not unexpected since raw material is no-to-rarely available, as it is here and in neighbouring Asia (Field data, D Bhalla 2016).

We estimated that about 15 kilos of PB became available over an annual period. Thus, in comparison to African countries, Bhutan is doing a better job to make speciality essential medications available in the country, at least to some extent. For instance, in 14 African countries, a subset of 20 basic essential medicines were found to severely lack in their availability at all levels of healthcare and distribution [28]. In such a scenario where ready (and essential) solutions are not sufficiently becoming available for the patients, we may not expect to bridge our goals related to reducing the treatment gap and public health burden of treatable conditions. Not surprisingly, PB is formally recognised as "missing in action" despite having a favorable efficacy and safety profile [20].

The reason that $\mathrm{PB}$ gets freely imported here is that all healthcare functions are predominantly public in nature. This differs from other countries where public system is not strong and sufficient and private agencies are subjected to restrictions $[6,7]$ (Field data, D Bhalla, 2016). Such restrictions are seen to push private stakeholders towards "easier" substances and away from the business of PB [29]. Few ministries elsewhere have realised the need of engaging private agencies to meet their healthcare goals for their own benefit and of their patients [30]; which Bhutan has yet to learn. Few ministries have also had their epilepsy control programs based principally on PB [31, 32].

Here, $\mathrm{PB}$ was available in $30 \mathrm{mg}$ dose strength, which certainly require patients to take multiple tablets at a single time, several times a day. This is an important factor towards inconvenience and non-adherence [11]. Similarly, pediatric PB syrups were absent as in other countries like Brazil, Nepal [3] (Field data, D Bhalla, 2016), an important system-related deficiency.

Here, about $36.0 \%$ of PB was at BHUs i.e. supposedly 'nearest' to the population, Table 1 . On the positive side, this is a better situation than elsewhere, for instance in 14 African countries, basic essential medications were available at $18-48.0 \%$ of primary health centers alone [28]. On the negative side, being 'nearest' may have a different context here since only $62.0 \%$ of this country is paved. Although the target is to keep the whole population within $3 \mathrm{Km}$ walking distance [33], this would still not be an ideal situation [34, 35]. Lastly, as is the case with PB here, complex neuropsychiatric topics are often projected through negativity and continual transfer of bydefault opinions from one to another, as the author has shown for Asia, Africa, Middle-east and North Africa, South America, The Caribbean [36], causing undue fear, negativity, and erroneous conclusions.

Our topic was suitable, of immense need and relevance, and was addressed through one scientifically-silent country [10] by using a simple replicable method. The topic has multiple dimensions as shown above. Our work also helped to advance global goals and recommendations such as the need for promotion of research and education on epilepsy, publication of detailed public health assessments etc. [22]. Our work also helps to focus on better use of "ready solutions" of which many patients may remain largely un-benefitted $[6,11,31,32]$.

To conclude, Bhutan does not manufacture PB (and all other ASMs) and annually makes available about 15 kilos of PB. This mainly happens because of the public nature of all healthcare functions here. In terms of sufficiency and making available specialised essential medications, Bhutan is doing a better job than many African countries. However, the possible therapeutic participation of $\mathrm{PB}$ in managing disease conditions (like epilepsy) likely to remain limited despite favorable safety and efficacy profile. There is a need to strengthen the availability of essential medications to reduce the treatment gap and public health burden of treatable disease conditions through fuller use of ready solutions. There is also a need to overcome challenges of inappropriate dose strength, absent pediatric formulation, indirect cost, and low selling price of PB.

\section{Limitations}

The limitations may include that we restricted ourselves, out of convenience and complexity, to $\mathrm{PB}$ alone although many other ASMs (including diazepam, phenytoin, sodium valproate) are possibly available. However, the question 
here was not just what is available but how much is available, and what level of treatment coverage may possibly be achieved with current quantity of one essential, affordable, and feasible medication. We currently do not know what proportion of patients are possibly treated with each ASMs in Bhutan, which is an important future question. The sufficiency projection may vary, but not our principal result about the quantity, depending upon how many are to be treated with PB. Our work did also not take into account projections for other disease conditions where $\mathrm{PB}$ is indicated, and also for the requirement due to incident cases and duration beyond 1 year.

\section{Abbreviations}

ADD: average daily dose; ASM: anti-seizure medication; BHU: basic health unit; PB: phenobarbital; PEP: prevalent epilepsy patient population.

\section{Authors' contributions}

All participants made equal contribution. The author read and approved the final manuscript.

\section{Author details \\ ${ }^{1}$ Sudan League of epilepsy and Neurology (SLeN), Khartoum, Sudan. ${ }^{2}$ Nepal Interest Group of Epilepsy and Neurology (NiGEN), Kathmandu, Nepal. ${ }^{3}$ Iran} Epilepsy Association, Teheran, Iran.

\section{Acknowledgements}

We acknowledge support of all participants, named or unnamed that might be.

\section{Competing interests}

The author declares that there is no competing interests.

\section{Availability of data and materials}

No individual participant identification data (incl. images, videos, voice recordings etc.) is reported. All possible data has been summarized and provided in the manuscript. All data is available to the original authors, it can not be deposited to any exernal location. Although discouraged, the datasets used and/or analysed during the current study are available from the corresponding author on reasonable request, if permission is granted by all stakeholders and local laws.

\section{Consent for publication \\ Not applicable.}

Ethics approval and consent to participate

Not applicable

\section{Funding}

Not applicable.

\section{Publisher's Note}

Springer Nature remains neutral with regard to jurisdictional claims in published maps and institutional affiliations.

Received: 26 April 2018 Accepted: 19 July 2018

Published online: 02 August 2018

\section{References}

1. WHA. WHA31.32. Action programme on essential drugs. In: WHO, editor. Handbook of resolutions and decisions of the World Health Assembly and the Executive Board. II (1973-84). Geneva; 1985. p. 129-30.
2. WHO. Communicable disease cluster: removing obstacles to healthy development: report on infectious diseases. Geneva: World Health Organization; 1999

3. Bhalla D, Lotfalinezhad E, Kapoor S, et al. Anti-epileptic drugs: is terminology appropriate? A change might be needed. Neurol Asia. 2015;20:117.

4. Kwan P, Browdie MJ. Phenobarbital for the treatment of epilepsy in the 21st century: a critical review. Epilepsia. 2004;45:1141-9.

5. Yasiry Z, Shorvon SD. How phenobarbital revolutionized epilepsy therapy: the story of phenobarbital therapy in epilepsy in the last 100 years. Epilepsia. 2012;53(Suppl 8):26-39.

6. Bhalla $D, A z i z H$, Bergen $D$, et al. Undue regulatory control on phenobarbital-an important yet overlooked reason for the epilepsy treatment gap. Epilepsia. 2015;56(4):659-62.

7. Chomba EN, Haworth A, Mbewe E, et al. The current availability of antiepileptic drugs in Zambia: implications for the ILAE/WHO "out of the shadows" campaign. Am J Trop Med Hyg. 2010;83(3):571-4.

8. GNHC. Bhutan population perspective plan. Gross National Happiness Commission, 2011 2010. Report No.

9. Tran BX, Nguyen LH, Nong VM, et al. Health status and health service utilization in remote and mountainous areas in Vietnam. Health Qual Life Outcomes. 2016;14:85.

10. Bhalla D. Knowledge, attitude, and practice among practitioners regarding epilepsy in Bhutan: a rural and a remote country. J Neurosci Rural Pract. 2017:8(4):507-10.

11. Hun C, Hok T, Bhalla D. Epilepsy: some controversies, some knowledge and some experience from Cambodia. Neurol India. 2014;62(6):606-9.

12. Brodie MJ, Kwan P. Current position of phenobarbital in epilepsy and its future. Epilepsia. 2012;53(Suppl 8):40-6.

13. Mattson RH, Cramer JA, Collins JF, et al. Comparison of carbamazepine, phenobarbital, phenytoin, and primidone in partial and secondarily generalized tonic-clonic seizures. N Engl J Med. 1985;313(3):145-51.

14. Wang WZ, Wu JZ, Dai XY, et al. Evaluation of the efficacy of phenobarbital in treatment of epilepsy in rural areas: study of 2455 patients in rural China. Zhonghua Yi Xue Za Zhi. 2006;86(19):1297-300.

15. Sykes RM. Epilepsy in children in Benin city, Nigeria. Ann Trop Paediatr. 2002:22(3):287-96.

16. Zhang LL, Zeng LN, Li YP. Side effects of phenobarbital in epilepsy: a systematic review. Epileptic Disord. 2011;13(4):349-65.

17. Gunnell D, Hawton K, Murray V, et al. Use of paracetamol for suicide and non-fatal poisoning in the UK and France: are restrictions on availability justified? J Epidemiol Community Health. 1997;51(2):175-9.

18. Gorton HC, Webb RT, Kapur N, et al. Non-psychotropic medication and risk of suicide or attempted suicide: a systematic review. BMJ Open. 2016;6(1):e009074.

19. Brodie MJ, Barry SJE, Bamagous GA, et al. Patterns of treatment response in newly diagnosed epilepsy. Neurology. 2012;78(20):1548-54.

20. Ilangaratne NB, Mannakkara NN, Bell GS, et al. Phenobarbital: missing in action. Bull World Health Organ. 2012;90(12):871.

21. DMS. Medical supplies and health infrastructure Thimphu, Bhutan: Department of Medical supplies. http://www.dved.gov.bt/. Accessed 10 June 2016.

22. Declaration of Santiago on epilepsy in Latin America. Epilepsia. 2002:43(Suppl 6):42.

23. Bhalla D, Tchalla AE, Marin B, et al. Epilepsy: Asia versus Africa. Epilepsia. 2014;55(9):1317-21.

24. NSB. Census reports-Bhutan Thimphu, Bhutan. http://www.nsb.gov.bt/ publication/publications.php?id=2. Accessed 10 July 3016.

25. Kaplan K, Laing R. Local production of pharmaceuticals: industrial policy and access to medicines-an overview of key concepts, issues and opportunities for future research Washington, USA: The International Bank for Reconstruction and Development/The World Bank; 2005. http:// medeor.de/images/themen/konferenz/KaplanLocalProductionFinal5b15 d.pdf. Accessed 10 July 3016.

26. Owoeye OA. Compulsory patent licensing and local drug manufacturing capacity in Africa. Bull World Health Organ. 2014;92(3):214-9.

27. Arzeno N, Diaz R, Gonzalez S. Brazil's generic drug manufacturing success and the policies that permitted it 2004 contract no: $10 \mathrm{Jul}$.

28. Robertson J, Forte G, Trapsida JM, et al. What essential medicines for children are on the shelf? Bull World Health Organ. 2009;87(3):231-7.

29. Subedi M. Trade in health service: unfair competition of Pharmaceutical products in Nepal. Dhaulagiri J Sociol Anthropol. 2009;3:123-42. 
30. $\mathrm{MOH}$. Child-specific medicine prices, availability, affordability-executive summary. Accra: $\mathrm{MOH} ; 2010$

31. Bhalla D. Domestic health visiting: an innovative approach to bridge Gaps in epilepsy care in Laos and Cambodia. Varetz; 2012.

32. Bhalla D. Epilepsy in Cambodia: results and perspectives. Ho Chi Minh, Vietnam: Impact Mental Health; 2011.

33. $\mathrm{MOH}$. National health policy. Thimphu: Ministry of Health; 2016

34. Chin JH. Epilepsy treatment in sub-Saharan Africa: closing the gap. Afr Health Sci. 2012;12(2):186-92.
35. Carter JA, Molyneux CS, Mbuba CK, et al. The reasons for the epilepsy treatment gap in Kilif, Kenya: using formative research to identify interventions to improve adherence to antiepileptic drugs. Epilepsy Behav. 2012;25(4):614-21.

36. Bhalla D, Lotfalinezhad E, Amini F, et al. Incidence and risk profile of dementia in the regions of Middle-East and North Africa (MENA). Neuroepidemiology. 2018 (In Press).
Ready to submit your research? Choose BMC and benefit from:

- fast, convenient online submission

- thorough peer review by experienced researchers in your field

- rapid publication on acceptance

- support for research data, including large and complex data types

- gold Open Access which fosters wider collaboration and increased citations

- maximum visibility for your research: over $100 \mathrm{M}$ website views per year

At BMC, research is always in progress.

Learn more biomedcentral.com/submissions 